\title{
Comparative ecology of clonal plants
}

\author{
J. M. VAN GROENENDAEL L 1 , L. KLIMEŠ $\check{S}^{2}$ J. KLIMEŠOV Á ${ }^{2}$ \\ AND R.J.J. HENDRIKS ${ }^{1}$ \\ ${ }^{1}$ Department of Ecology, University of Nijmegen, Toernooiveld 1, NL-6525 ED Nijmegen, The Netherlands \\ ${ }^{2}$ Institute of Botany, Section of Plant Ecology, Academy of Sciences of the Czech Republic, Dukelska 145, 37982 Treboñ, \\ Czech Republic
}

\begin{abstract}
SUMMAR Y
Somatic embryogenesis is a phylogenetically ancient trait that allows sessile plants to grow in a modular fashion and to respond plastically to different environmental cues. It facilitates damage repair and permits clonal growth, the capacity to produce potentially independent but genetically identical offspring. Clonal growth is observed to originate from both the shoot or the root part of the plant body and it has been assigned various ecological functions such as reproduction, exploitation and persistence. These functions are rooted in two basic morphological characteristics of clonal growth: the longevity and the length of the connection between clonal parts. Clonality, although an ancient trait, shows a polyphyletic distribution among plant taxa with a strong representation especially among monocots. Phylogenetically controlled comparisons show that clonality is more common among species that occur in cold or nutrient-poor habitats and under poor light conditions. The frequent occurrence of clonals among aquatic species is confounded by the fact that many aquatics are monocots. This however does not necessarily preclude a functional ecological explanation. It is further shown that longevity and length of connection covary negatively, yielding two distinct clonal growth strategies (fragmenting versus compact, persistent clones) with a preference for the more common habitat trait combinations: nutrient-rich, shaded and/or wet versus nutrient-poor, open and/or dry, respectively.
\end{abstract}

\section{INTRODUGTION}

The specific capacity of plants to grow and reproduce clonally has had a continuous attraction for botanists. Detailed accounts of the morphology and anatomy of clonal plants exist from the middle of last century onwards (Irmisch 1850; Velenovský 1907-1913; Goebel 1928-1933; Rauh 1937; Troll 1937-1942; Salisbury 1942; Leakey 1981). More recently research has focused on the functionality of this fascinating complex of traits in adapting clonal plants to their environment (Harper 1977; Jackson et al. 1985; van Groenendael \& de Kroon 1990; Callaghan et al. 1992; Soukupová et al.1994; de Kroon \& van Groenendael 1997; Oborny \& Podani 1996). Understanding the role of clonality in plants requires an integrated approach and cannot be achieved without understanding the morphological basis and its phylogenetic origin (Tiffney \& Niklas 1985; Mogie \& Hutchings 1990) that put boundaries to the functioning of clonal structures, and without knowledge of the growth rules that cause the specific spatial 'behaviour' of clonal plants (Bell 1991; Hutchings \& de Kroon 1994; Oborny 1994). We equally require insight into the physiology of modularly organized systems (Watson \& Casper 1984; Marshall 1990; Stuefer et al. 1994), that affect the direct performance of clonal organisms and we need to know the genetic (Ellstrand \& Roose 1987; Eriksson 1993; Widén et al. 1994) and evolutionary (Tuomi \& Vuori- salo 1989; Eriksson \& Jerling 1990; Schmid 1990) consequences of asexual reproduction that affect the performance of clonal organisms in the long run.

Before we can start discussing constraints and mechanisms of the clonal growth form in the context of the functions of clonal growth, we need to define what constitutes a clonal plant. In the broadest sense, all plants are essentially clonal. Due to the late specialization of the plant cell, its so called long-preserved totipotency, and due to its modular construction where each module contains both somatic and meristematic tissue, all plants are potentially clonal and can be made to regenerate from plant parts. A reasonable working definition, however, is to describe a clonal plant as a plant capable of naturally producing potentially independent offspring by means of vegetative growth. This definition allows plants to be classified as clonal or non-clonal.

Broadly speaking two approaches have been and still are followed to further our understanding of the role of clonality in adapting plants to their environment. The first approach and also the approach that will be adopted in this paper, is empirical and comparative and tries to achieve comprehensive descriptions of the patterns of distribution of clonality. The quality of such pattern analysis depends on both precise trait definition and precise habitat description and the analysis will ultimately produce inferences about the function of clonality, based on better insights in the various clonal 
growth forms and their interrelations. The possibilities for such pattern analysis are now becoming increasingly better because of the increasing availability of large sets of data on local floras that allow critical comparisons to be made. What do we know so far about the patterns of distribution of clonal plant species over various habitats and over various plant communities? We know from field experience and published accounts that there exists an uneven distribution of clonal growth forms. Clonal growth is assumed to be more abundant in the arctic than in temperate regions (Perttula 1941; Callaghan et al. 1992), more abundant in aquatic habitats than in terrestrial ones (Duarte et al. 1994), more abundant in shady habitats such as forest understorey and possibly more abundant under nutrient-limited conditions than under nutrient-rich conditions.

The second approach tries to unravel the working mechanisms in clonally organized plants and to demonstrate experimentally the costs and benefits involved in enhancing plant performance, working from hypotheses that functionally relate form and the patterns of distribution. The main functions ascribed to clonality can be divided into four categories: asexual recruitment, adult persistence, spatial mobility and storage.

It has been assumed, for instance, that the high risks involved in realizing pollination in submerged aquatic macrophytes, have promoted clonal growth forms because these allow the production of asexual propagules (Duarte et al. 1994). Clonal fragmentation is a way to reduce the mortality risks of the genet and to produce an array of phenotypes from the same genotype (Eriksson \& Jerling 1990) thus retarding the loss of genetic variation within populations (Silander 1985; Ellstrand \& Roose 1987; Widén et al. 1994).

Low seedling recruitment in arctic habitats is compensated for by clonal persistence of established adults (Callaghan et al. 1992). Clonal persistence also allows the long-term occupation of a site which is assumed to be an advantage when resources are scarce and need to be monopolized (de Kroon \& Schieving 1990).

Through clonal growth, spatially distributed limiting resources can be exploited (Lovett Doust 1981; Alpert \& Mooney 1986; Hutchings \& de Kroon 1994; de Kroon \& Hutchings 1995). It also enables growth in patchy environments, characterized by the simultaneous contrasts in more than one resource, achieving a certain division of labour (Stuefer et al. 1994, 1996; de Kroon et al. 1996).

Clonal plants can utilize stored reserves to tide them over difficult periods or give them a headstart at the beginning of a growing period (Shaver \& Billings 1976; Klimeš et al. 1993; Geber et al. 1996). Not enough is known however about the costs and benefits of storage and remobilization of reserves so frequently stored in the clonal organs (Chapin et al. 1990).

Combining pattern and process in this functional way carries in itself two risks. The first one is that working mechanisms may be demonstrated for one species but may not be valid for others (Hutchings \& de Kroon 1994; Kelly 1994). The second one and the one most relevant in the context of this paper, is the assumption that pattern reflects function. The clonal traits that we are studying might not be the result of an optimization process such as current selection but the remnants of past evolutionary history (Gould \& Lewontin 1979) or a byproduct of selection for a different trait and this might seriously confound the functional relations we are trying to infer from a match between trait distribution and habitat distribution (Felsenstein 1985; Harvey et al. 1995; Westoby et al. 1995). Phylogeny is likely to be of importance, especially when dealing with clonal traits. As shown by Tiffney \& Niklas (1985) and by Mogie \& Hutchings (1990) the first vascular plants were clonal, but ancestors of the seed plants were woody and nonclonal, traits maintained among most gymnosperms. Also the progenitor of the angiosperms is assumed to be non-clonal (Kelly 1995). Within the class of angiosperms the capacity for clonal growth became most prominent among the monocots that show reduction of secondary thickening and secondary monopolarity. Among dicots the pattern is more diversified. As pointed out by the above authors it is in fact clonality that we need to consider as the derived trait among the seed plants.

The clonal growth characteristics that critically determine the performance of clonal plants under these various hypotheses of their function, are basically few: the longevity of the functional connection between mother and daughter ramets; the distance between them; and the frequency and angle of branching. However, the morphological basis - the way a particular species realizes these traits - is much more varied and spans a range of morphologies, depending on the origin of meristems and their vascular connections within the clonal structures and the phyletic lineage of the species, each one imposing its own limitations on the ecological functions that we attribute to clonal growth.

What we set out to achieve in this paper is to compare a large number of species with respect to their clonal characteristics and to relate these characteristics to the known habitat preferences of these species. More specifically we wanted to explore the distribution of clonal traits over environmental gradients and to test the preference of clonal species for wetter, more resource poor and colder environments, to examine the assumed phylogenetic constraints in clonal traits and to test the degree to which the previously established trait-environment relationships are affected by a possible phylogenetic heritage.

\section{GOMPARATIVE ANALYSIS}

To answer the questions raised above the flora of central Europe containing some 2300 species has been subjected to a comparative analysis. For each species the following data have been compiled:

1. Habitat preference based on indicator values according to Frank \& Klotz (1990; largely adapted from Ellenberg 1991 to fit central European con- 


\begin{tabular}{|c|c|c|c|c|}
\hline & \multicolumn{2}{|c|}{ non-spreading } & \multicolumn{2}{|c|}{ spreading } \\
\hline 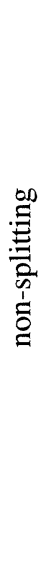 & $\begin{array}{l}\text { disintegrating } \\
\text { Trip root } \\
\text { below-ground stem }\end{array}$ & $\begin{array}{l}\text { turf graminoid } \\
\text { Festuca ovina } \\
\text { long-living tuber } \\
\text { Corydalis cava }\end{array}$ & $\begin{array}{l}\text { roots with } \\
\text { adventitious buds } \\
\text { Rumex acetosella } \\
\text { long-living } \\
\text { epigeotropic } \\
\text { below-ground stem } \\
\text { Rumex alpinus }\end{array}$ & $\begin{array}{l}\text { long-living above- } \\
\text { ground creeping stem } \\
\text { Lycopodium annotinum } \\
\text { long-living } \\
\text { hypogeotropic } \\
\text { below-ground stem }\end{array}$ \\
\hline 点 & $\begin{array}{l}\text { root-originating } \\
\text { tuber } \\
\text { Ranunculus ficaria } \\
\text { below-ground stem }\end{array}$ & $\begin{array}{l}\text { short-living tubers } \\
\text { attached } \\
\text { Ornithogalum gussonei }\end{array}$ & $\begin{array}{l}\text { short-living } \\
\text { plagiotropic } \\
\text { above-ground stem } \\
\text { bragaria vesca } \\
\text { below-ground }\end{array}$ & $\begin{array}{l}\text { short-living } \\
\text { hypogeotropic } \\
\text { below-ground stem } \\
\text { Asperula odorata } \\
\text { Dentaria bullary buds }\end{array}$ \\
\hline
\end{tabular}

Figure 1. Various forms of clonal structures categorized according to their capacity to spread and the longevity of their connection. Origin of clonal structure and examples of species are given for each of the four categories.

ditions). Indicator values range from $1-9$ (and in the case of availability of water from 1-12) in an ordinal scale indicating a species preference in an environmental gradient. These gradients span habitats with low to high availability of light, nutrients, water or with low to high mean annual temperature.

2. Presence or absence of clonality, based on a comprehensive survey of the literature supplemented with extensive field observations. Morphological origin of the connection between shoots: root- or shootderived. Longevity of connection in two categories: longer or shorter than one year and lateral spread in $\mathrm{cm}$ also in two categories: longer or shorter than $25 \mathrm{~cm}$. The more common clonal structures are categorized and presented in figure 1. (For a more extensive description and finer details of clone morphology, not used in this paper, see Klimeš et al. 1997).

3. The phylogenetic lineage of each species was established by placing each species in its family according to its current taxonomic position and relating families according to Chase et al. (1993), using one randomly selected tree from their second search and restricted to the plant families present in the central European flora.
On the species level we related clonal traits to habitat preference in a hierarchical fashion. First we contrasted the frequency distributions of clonal and non-clonal plants over the four major ecological gradients. Each of these corresponds to expectations based on larger geographic patterns predicting that clonal plants should be more frequent under wet conditions than under dry conditions, more frequent under nutrient limited conditions compared with nutrient rich conditions, more frequent in the shade and at low mean annual temperatures. The frequency distributions were tested by straightforward Kruskal Wallis tests (SAS release, SAS/STAT 1990). In a second step, we analysed the frequency distribution of specific clonal traits over the selected environmental gradients within the group of clonal plants. We used simple dichotomies: root- or shoot-derived clonal structures; long-lived or short-lived clonal connection and extension of clonal spread larger or smaller than $25 \mathrm{~cm}$. The contrasting frequency distributions were tested in the same way as those above. Unlike the distribution of clonality over environmental gradients, we had no a priori expectations of the various distributions of clonal traits over the four major 
1334 J. M. van Groenendael and others Comparative ecology of clonal plants

Table 1. Medians of the frequency distribution of Ellenberg indicator values of (a) clonal and non-clonal plant species from the central European flora and (b) clonal species with respectively root or shoot derived clonal structures, short- or long-lived ( $>1 \mathrm{yr})$ connections, and short- or long-distance $(>25 \mathrm{~cm})$ capacity to spread

(Ellenberg values indicate low to high: availability of water (range 1-12); availability of nutrients (range 1-9); mean annual temperature (range 1-9); and availability of light (range 1-9) $p$ values of Kruskal-Wallis test of difference in parentheses. In cases with significant differences between distributions but equal median valus + and - signs indicate the direction of the difference.)

\begin{tabular}{|c|c|c|c|c|c|c|c|c|}
\hline & \multicolumn{2}{|l|}{ moisture } & \multicolumn{2}{|l|}{ nutrients } & \multicolumn{2}{|c|}{ temperature } & \multicolumn{2}{|l|}{ light } \\
\hline & median & $\mathrm{n}$ & median & $\mathrm{n}$ & median & $\mathrm{n}$ & median & $\mathrm{n}$ \\
\hline \multicolumn{9}{|l|}{ (a) } \\
\hline clonal & 5 & 816 & 4 & 742 & 5 & 587 & $7-$ & 851 \\
\hline non-clonal & $\begin{array}{l}4 \\
(0.0001)\end{array}$ & 481 & $\begin{array}{l}5 \\
(0.0001)\end{array}$ & 429 & $\begin{array}{l}6 \\
(0.0001)\end{array}$ & 431 & $\begin{array}{l}7+ \\
(0.0001)\end{array}$ & 536 \\
\hline \multicolumn{9}{|l|}{ (b) } \\
\hline root-derived & 4 & 125 & 3 & 115 & 6 & 99 & $7+$ & 138 \\
\hline shoot-derived & $\begin{array}{l}6 \\
(0.0001)\end{array}$ & 699 & $\begin{array}{l}4 \\
(0.016)\end{array}$ & 610 & $\begin{array}{l}5 \\
(0.0001)\end{array}$ & 477 & $\begin{array}{l}7- \\
(0.0007)\end{array}$ & 696 \\
\hline long-lived & 5 & 628 & 4 & 592 & 5 & 469 & $7+$ & 665 \\
\hline short-lived & $\begin{array}{l}7 \\
(0.0001)\end{array}$ & 199 & $\begin{array}{l}5 \\
(0.0001)\end{array}$ & 162 & $\begin{array}{l}6 \\
(\mathrm{NS})\end{array}$ & 127 & $\begin{array}{l}7- \\
(0.0001)\end{array}$ & 199 \\
\hline spreading $<25 \mathrm{~cm}$ & 5 & 454 & 4 & 417 & 6 & 355 & 7 & 482 \\
\hline spreading $>25 \mathrm{~cm}$ & $\begin{array}{l}7 \\
(0.0001)\end{array}$ & 334 & $\begin{array}{l}5 \\
(0.0015)\end{array}$ & 297 & $\begin{array}{l}5 \\
(0.0099)\end{array}$ & 213 & $\begin{array}{l}7 \\
(\mathrm{NS})\end{array}$ & 338 \\
\hline
\end{tabular}

environmental gradients. Theoretically one would expect a relationship between the capacity to spread and environmental heterogeneity (Cain 1994; Slade \& Hutchings 1987; Sutherland \& Stillman 1988). As to the longevity of the connection one would expect 'splitting clones' to be more abundant in habitats with frequent random disturbance (Eriksson \& Jerling 1990). However, as environmental heterogeneity and disturbance are usually defined in relation to specific species, it is very difficult to quantify environmental gradients of heterogeneity and disturbance in an operational, non-circular way. The third step maps clonality on to the Chase phylogeny to see whether clonality shows a phylogenetic pattern that could affect the distribution patterns compiled from the database above. The Chase phylogeny is based on molecular data, independent from the morphological trait that is mapped on to it but, as the phylogeny is worked out at the family level only, the mapping is done for percentage occurrence of clonal species within a family. This introduces two possible sources of error. The first one is the sometimes insecure assignment of species to higher order taxa as this assignment is based on current, largely morphological criteria. The second one is that some families, especially those with a centre of distribution outside central Europe, are not fairly represented by the species in the database. However, it is not very likely that these sources of bias affect clonal and non-clonal species differently. In a last step the trait-environment relations are re-analysed on the level of the family while taking into account the phylogenetic descendance of such a taxon, using the method of independent contrasts (Harvey \& Pagel 1991) and the GAIc algorithm (Purvis \& Rambaut 1995). To reduce estimation errors in calculating family mean values of the relevant parameters, families containing less then five species where excluded. Contrasts were drawn with the independent environmental contrasts on the $\mathrm{X}$-axis and the clonal trait contrasts on the $\mathrm{Y}$-axis and tested for significant relationships using regression through the origin.

\section{RESULTS}

A simple comparison of the frequency distribution of the occurrence of clonality against the major environmental gradients shows a clear distinction between clonal and non-clonal species (table 1). Clonal species are more frequent in wet habitats, under nutrient-poor conditions, at lower mean temperatures and also, although less clearly so, at lower light availability. This confirms at the species level and at the scale of a regional flora, the qualitative observations from geographical patterns of distribution. This provides a strong basis for further extending functional theories to explain the observed trait-environment relationships.

Within the group of clonal plant species, clonality originates more frequently from stem structures compared with root-derived origins. The origin of a clonal structure is not randomly distributed over the major ecological gradients but sometimes shows clear preferences (table 1). Quite obviously stem-derived clonal structures prevail in wet and aquatic habitats, but they are also more frequent under nutrient-rich conditions and under low light intensities. Fragmenting clones are less frequent then connected, persistent systems and show a preference for wet conditions and for nutrientrich conditions (table 1). Lastly, the capacity to spread is more evenly distributed over all clonal species but is also affected by habitat (table 1) in more or less the same fashion as longevity of connection was affected, with a preference for spreading in wet and in nutrientrich habitats. 


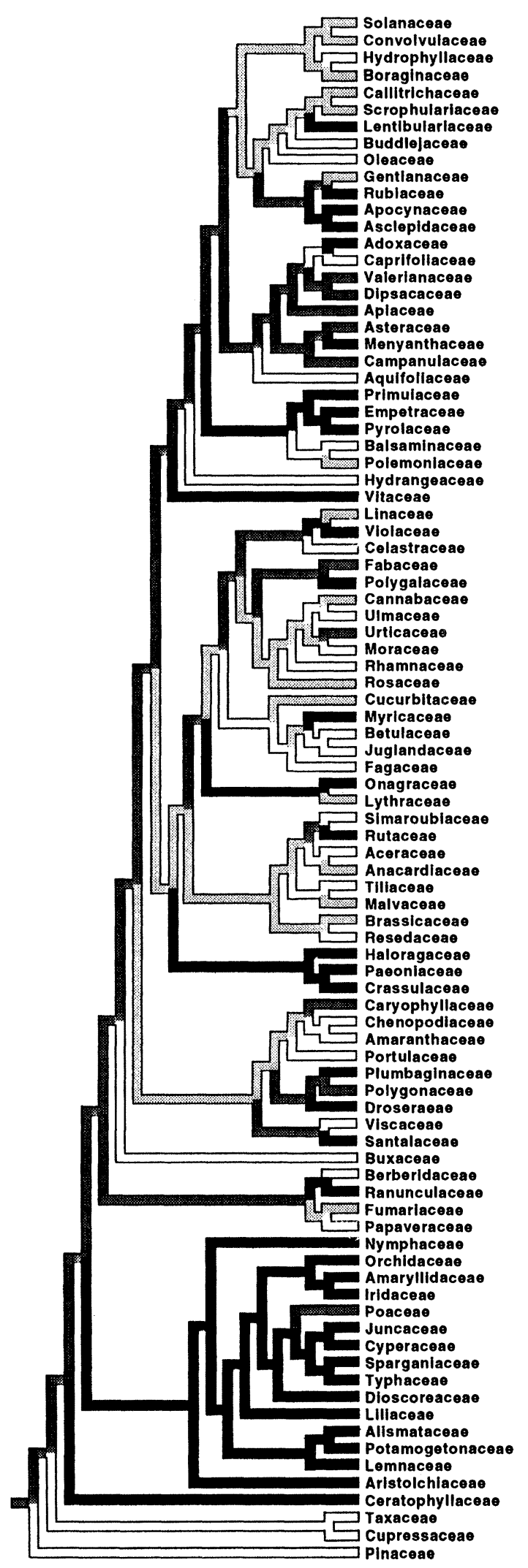

Figure 2. Hypothetical reconstruction of the distribution of clonality over gymnosperm and angiosperm plant families from the central European flora, derived from weighted averages based on current frequency of clonality among extant plant families. Intensity of shading corresponds to increasing frequency of clonal species: solid denotes 75$100 \%$; dark stippling denotes $50-75 \%$; light stippling denotes 25-50\%; open denotes 0-25\%. Phylogeny based on Chase et al. (1993).
Table 2. The distribution of clonality over genera represented by more than five species, for the subclasses of monocots and dicots

\begin{tabular}{lclc}
\hline & monocots & dicots & total \\
\hline fully clonal & 20 & 25 & 44 \\
mixed clonality & 9 & 58 & 67 \\
fully non-clonal & 0 & 14 & 15 \\
total & 29 & 97 & 126 \\
\hline
\end{tabular}

Looking at the mapping of the degree of clonality over the plant families present in the dataset, one can observe a phylogenetic pattern (figure 2). It is clear that there exists a relationship between monopolarity of the growth pattern, growth from one end only and the occurence of or rather necessity for clonal growth. Within the monocots, which as a group show secondary loss of bipolarity early during embryogenesis, the inferred frequency of clonal growth is apparently much higher than in the dicots, which maintain their bipolarity in the entire subclass. The gymnosperms as a more ancient group are distinguished by their lack of clonality. Further down the phylogenetic tree, more phylogenetic effects become visible (figure 2). Among the clonal monocot families some loss of clonality has occurred within the grass family. Among the large group of dicot families a much more diversified and polyphyletic pattern can be inferred indicating the appearance and disappearance of clonal forms. This pattern is maintained at the lower level of genera. Among the genera with more then five species (126 genera in all) more than half of these show mixed clonality, that is that some species in the genus are clonal and others are not. This phylogenetic trend is not restricted to dicot genera but also clearly present among monocot genera (nine out of 29 contain both clonal and non-clonal growth forms; table 2).

Given the phylogenetic pattern that one can observe in figure 2, there are grounds to re-analyse the speciesenvironment relations presented above. Especially when certain environments are dominated by monocots such as grasslands, sedge meadows and also aquatic habitats (Duarte et al. 1994). This could clearly affect general conclusions with respect to the adaptive value of clonality in these habitats. Given the restrictions imposed by the phylogeny, this re-analysis is confined to the family level. As one could expect by averaging the trait and habitat values over families, the trait-environment relationships become more robust. Nevertheless, contrary to the null hypothesis of no higher order phylogenetic effects, a number of relationships are maintained, notably the relation between nutrient levels and clonality, between water availability and clonality, between water availability and longevity of connection and between water availability and spreading, indicating higher level taxonomic effects and thereby possibly phylogenetic rather then ecological relationships (table 3 ). When correcting for phylogenetic bias, out of the four strong relationships mentioned, the relationship between water availability and clonality disappears (table 3), while others are maintained. This implies that at least at the level of the 
Table 3. (a) The relationship between percentage clonality and mean Ellenberg indicator values per family for four environmental gradients expressed as Pearson correlation coefficients and (b) independant contrasts based on the GAIG algorithm (Purvis \& Rambaut 1995) calculated for percentage clonality and mean Ellenberg indicator values per family

(The significance of the regression through the origin of the environmental gradient contrasts onto the clonality contrasts is given.)

\begin{tabular}{lcccc}
\hline & moisture & nutrients & temperature & light \\
\hline$(a)$ & 0.31 & 054 & 0.30 & 0.08 \\
correlation coefficient & 48 & 47 & 47 & 48 \\
$n$ & $p<0.0320$ & $p<0.0001$ & $p<0.0365$ & n.s. \\
significance & 47 & 46 & 46 & 47 \\
$(b)$ & $p<0.12$ & $p<0.0008$ & $P<0.0211$ & n.s. \\
$n$ & & & & \\
significance & & & & \\
\hline
\end{tabular}

family the relationship between water availability and clonality has a strong phylogenetic component.

\section{DISGUSSION}

The comparative approach is one of the basic tools that provides the empirical basis for a scientific discipline, where observed patterns can be matched against theoretical expectations and used to generate hypotheses. Clearly, comparing species' traits and environmental characteristics is a way to achieve these goals in ecology. It is also clear that the criticism by Felsenstein and others on the comparative approach (e.g Felsenstein 1985; Harvey et al. 1995) has something to contribute: there is a danger in considering species traits as independent measures of an ecological relationship as the actual relation is between individuals and their local environment. Inasmuch as the individual is part of a species it has a phyletic heritage constraining the traits and impacting on an individual's capacity to function. This criticism especially affects the evolutionary aspects of a species-environment relationship. Clearly, the direct effect of a trait on the functioning of an organism can be studied without paying much attention to the context into which such a trait is embedded: the breeding population of a species. It is when we cross the border between individual performance and individual fitness as most ecologists do, when we mix the proximate and the ultimate, that the phylogenetic constraints do become an important aspect.

Having said that the comparative approach has to be applied with care when trying to explain traitenvironment relationships as adaptations, because of the risk of phylogenetic constraints to be taken as adaptive traits, the reverse question immediately poses itself. Have phylogenetically conservative traits always to be treated as constraints or in other words, when we apply phylogenetic correction to our ecological comparisons of species, what is the risk that such a correction takes out meaningful trait-environment relationships just because they have happened to remain the same over evolutionary time? This has important methodological consequences. It implies that phylogenetic correction can support arguments but cannot disprove them. Whenever a trait-environment relationship across species holds after taking into account possible effects of phyletic heritage this provides strong corroboration of the adaptive value of such a trait, but the reverse is not necessarily true. As shown above the relationship between clonality and the availability of water in a habitat disappears when taking independent contrasts. The probable reason for this is the fact that most aquatic and semi-aquatic species are monocots, much more so compared to the presence of monocots in terrestrial habitats (Duarte et al. 1994). As pointed out by Duarte and his coworkers, plants have adapted to life in aquatic habitats from terrestrial ancestors. Given the specific problems of life under water, only a selected subset of available life forms actually succeeded, including a disproportionally large number of monocots. The main reason for this success they assume, is the capacity of monocots to reproduce asexually and thereby overcome the problems involved with sexual reproduction in aquatic environments. If this is true, then clonality has a clear ecological function among aquatics that is now obscured by the phylogenetic correction, designed to discriminate between ecological and phylogenetic arguments.

What remains as a conclusion is the fact that a comparative analysis of trait-environment relationships based on a large set of species has confirmed the main intuitive patterns upon which a number of hypotheses as to the function of clonal traits have been built: clonal plants are more abundant under wet, cold and unproductive circumstances. Why clonal plants are more abundant under these circumstances is still largely hypothetical. One could argue that these three habitats all present abiotic limitations to the growing conditions for plants. These are species-poor habitats in general and the species that do occur tend to be clonal. Clonality might be seen as a way of producing more feeding sites, conserving resources once acquired and providing a long life span by avoiding senescence as a way of overcoming sexual recruitment problems under unfavourable conditions. Although this seems intuitively appealing it is not certain that we can suffice with such a general hypothesis for clonality. One reason is the fact that among clonal plants themselves clonal traits show a different trend that seems to partly contradict the general idea of clonality as a way to survive cold, wet, resource-poor conditions. For instance, the tendency to spread as well as the tendency 


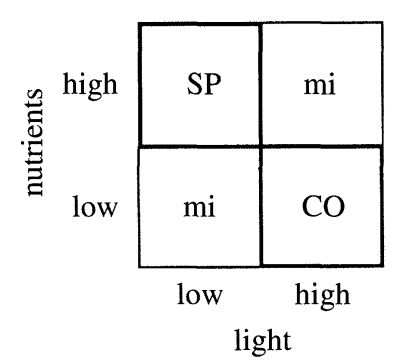

\begin{tabular}{|c|c|}
\hline mi & SP \\
\hline $\mathrm{CO}$ & $\mathrm{mi}$ \\
\hline low high \\
moisture
\end{tabular}

Figure 3. Environmental gradient space, showing in bold lining the significant negative association between nutrients and light $(R=-0.4066 ; p<0.0209 ; n=32)$ and positive association between nutrients and water availability $(R=$ $0.3112 ; p<0.0829 ; n=32)$. Covarying trait combinations ('clonal strategies') are mapped on this gradient space: short-lived, spreading connections (SPlitters) and long-lived, non-spreading connections (space COnsolidators). Other trait combinations are indicated as mixed (mi). Note the coincidence between covarying traits and habitat characteristics.

to split, is more frequent under wet and but also under nutrient rich and shaded conditions, whereas more falanx-like structures of tightly packed connected ramet systems occur under nutrient-poor but also dry and open non-shaded conditions. This suggests in the first place that there is covariation in clonal traits, linking the longevity of the connection to the distance of spreading. This is supported by the significant negative correlation between frequency of long-lived connections at the family level against frequency of long-distance spreading (Pearson $R=-0.3163, p=$ $0.0303, n=32$ ), although some of this relationship is lost when taking independent contrasts, probably because of the frequent occurrence of splitters among monocots and notably the aquatics among them $(p=$ 0.0729 for a regression through the origin). This suggests in the second place that it might be the combination of traits that responds to combined nutrient, light and moisture gradients. This is supported by the relations between mean Ellenberg values on the family level: preferences for nutrient-rich conditions covary negatively with the availability of light (Pearson $R=-0.4066, p=0.0209, n=32 ; p=$ 0.0038 for the regression through the origin for independent contrasts) and positively, although less clearly so, with the availability of moisture (Pearson $R=0.3112, p=0.0829, n=32 ; p=0.0796$ for the regression through the origin for independent contrasts). This is represented schematically in figure 3 . The preferred combinations of clonal traits are more abundant in the preferred combinations of environmental traits. Splitters (short-lived, long-distance connections) are preferably found under nutrient-rich and shaded or nutrient-rich and wet conditions and the reverse is true for tightly packed, connected systems. This supports the idea that covariation in environmental characteristics forms an important aspect in trying to understand the functionality of clonal traits or trait combinations (Stuefer et al. 1996).

The costs and benefits of the trade-off that suggests itself here are as yet not quantified, but longer connections represent larger initial investments (de
Kroon \& Schieving 1990) and more costs of maintenance. These costs of maintenance get higher the longer a functional connection is maintained. Longer connections might represent a demographic benefit of dispersal, placing offspring well away from the parent. As soon as the propagule is formed the connection is no longer functional and gets lost, leading to the splitting trait combination. Longer connections also allow the exploitation of resources outside ramet depletion zones or when resources are patchily distributed. Here costs and benefits can be measured more directly. A substantial initial investment represents a measurable risk and can be compared with the expectation of a return. Such risks are probably only worth taking in nutrient-rich habitats or in forest understorey where there are light gaps to be exploited. At the same time, a risky investment also invokes the need to restrict support when the investment is not returned, also leading to the trait combination of splitters. From a cost-benefit point of view, it will not always be easy to discriminate between the demographic benefit of asexual recruitment and the direct benefit of resource exploitation as the difference is mainly a question of timing. A new ramet can be produced more or less directly or after a phase of some sort of meristematic dormancy but in functional connection with the parent (Geber et al. 1996). However, when that connection gets lost before the ramet is produced, as in tuber or turion formation, the direct benefit is replaced by a longer-term demographic benefit that is much more difficult to quantify. An important but unknown aspect in this cost-benefit balance is the extent to which an unsuccesful initial investment can be recovered, as already noted by Pitelka \& Ashmun (1985). The fact is that long distance, short-lived connections (splitting clones) are relatively scarce among clonal plants (about $25 \%$ ) and occur under wet, shaded and nutrient-rich conditions. They probably represent a derived rather than ancestral trait combination contrary to the suggestion by Pitelka \& Ashmun (1985).

Functional connections in a tightly packed system are relatively cheap and easy to maintain. They are indeed more common and mostly found under limiting growing conditions in dry and nutrient-poor habitats. It is unlikely that ramets well within each other's zone of influence could be made independent and therefore exploitation of resources away from the parental depletion zone or asexual recruitment are unlikely explanations for the clonal trait combination of compact, long-lived tussock-like growth. Here the return on the investment might be the reduction of strong intra-clonal competition that favours total clone persistence and site occupation, monopolizing the nutrients present (Carlsson \& Callaghan 1990; Bullock et al. 1994). Another piece of evidence for covariation in persistence of connection and distance of spreading, is the fact that within species, notably those with commercial value, such as Festuca rubra and Trifolium repens, breeding has created a wide array of clonal forms ranging from dense persistent tussock-like forms to strongly rhizomatous fragmenting forms (and in the case of Trifolium also non-clonal annual forms; Sackville Hamilton, personal communication), indicating 
1338 J. M. van Groenendael and others Comparative ecology of clonal plants

at least for these species the presence of the necessary genetic covariation that could explain the concerted appearance and disappearance of this clonal trait combination.

In conclusion one can say that the large flora databases that are now becoming available are a rich source both for testing assumed ecological correlates, in this case trait-environment relationships in clonal plants, and exploring patterns that were not so obvious. The comparative method that generates these patterns, should be used with caution. On the one hand it could lead to unwarranted relations because constraints are taken for adaptations. On the other hand, the phylogenetic correction might point at an alternative explanation, it is not proof of such an alternative. Clonal plants are more frequent under wet, nutrientpoor and cold circumstances as expected but the functional relationships underlying such patterns are far less clear and require different hypotheses for different conditions. This is evident from the patterns of distribution of specific clonal traits, showing both covariation in traits and a preference of the trait combination to occur in specific combinations of environmental gradients. To better understand the partly conflicting functions assigned to clonal traits such as asexual reproduction versus resource exploitation or persistence versus fragmentation, cost-benefit analyses of clonal growth are required with emphasis on recovery of costs already made.

We thank Jonathan Silvertown and Michael Dodd for their contribution to a phylogenetically correct analysis of our clonal data, and Joop Ouborg and Hans de Kroon for their comments on an earlier version of the manuscript. JvG gratefully acknowledges the financial support of the European Science Foundation. LK and JK were supported by grant A6005606 of the Academy of the Czech Republic.

\section{REFERENGES}

Alpert, P. \& Mooney, H. A. 1986 Resource sharing among ramets in the clonal herb Fragaria chiloensis. Oecologia 70, 227-233.

Bell, A. D. 1991 Plant form: an illustrated guide to flowering plant morphology. Oxford University Press.

Bullock, J. M., Clear Hill, B. \& Silvertown, J. 1994 Tiller dynamics of two grasses: responses to grazing, density and weather. J. Ecol. 82, 331-340.

Cain, M. L. 1994 Consequences of foraging in clonal plant species. Ecology 75, 933-944.

Callaghan, T. V., Carlsson, B. A., Jonsdottir, I. S., Svensson, B. M. \& Jonasson, S. 1992 Clonal plants and environmental change. Oikos 63, 341-453.

Carlsson, B. A. \& Callaghan, T. V. 1990 Programmed tiller differentiation, intraclonal density regulation and nutrient dynamics in Carex bigelowii. Oikos 58, 219-230.

Chapin, F. S. III, Schulze, E.-D. \& Mooney, H. A. 1990 The ecology and economics of storage in plants. A. Rev. Ecol. Syst. 21, 423-447.

Chase, M. W. \& 41 co-authors 1993 Phylogenetics of seed plants: an analysis of nucleotide sequences from plastid gene $r b c$ L. Annls Missouri Bot. Gard. 80, 528-580.

Duarte, G. M., Planas, D. \& Peňuelas, J. 1994 Macrophytes, taking control of an ancestral home. In Limnology now: a paradigm of planetary problems (ed. R. Margalef), pp. 59-79. Amsterdam: Elsevier.
Ellenberg, H. 1991 Indicator values for plants in central Europe. Scripta Geobotanica 18, 1-248. (In German.)

Ellstrand, N. C. \& Roose, M. J. 1987 Patterns of genotypic diversity in clonal plant species. Am. J. Bot. 74, 123-131.

Eriksson, O. \& Jerling, L. 1990 Hierarchical selection and risk spreading in clonal plants. In Clonal growth in plants: regulation and function (ed. J. M. van Groenendael \& H. de Kroon), pp. 79-94. The Hague: SPB Academic Publishing.

Eriksson, O. 1993 Dynamics of genets in clonal plants. Trends Ecol. Evol. 8, 313-316.

Felsenstein, J. 1985 Phylogenies and the comparative method. Am. Nat. 125, 1-15.

Frank, D. \& Klotz, S. 1990 Biological-ecological data to the flora of the GDR. Wissenschaftliche Beitrage der Martin Luther Universität Halle-Wittemberg 32, 1-167. (In German.)

Geber, M., Watson, M. \& de Kroon, H. 1996 Development and resource allocation in perennial plants: the significance of organ preformation. In Plant resource allocation (ed. F. A. Bazzaz \& J. Grace). New York: Academic Press. (In the press.)

Goebel, K. 1928-1933 Organographie der Pflanzen, 3rd edn. Jena: Gustav Fischer. (In German.)

Gould, S. J. \& Lewontin, R. C. 1979 The spandrels of San Marco and the Panglossian paradigm: a critique of the adaptationist programme. Proc. R. Soc. Lond. B 205, 581-598.

van Groenendael, J. M. \& de Kroon, H. 1990 Clonal growth in plants: regulation and function. The Hague: SPB Academic Publishing.

Harper, J. L. 1977 Population biology of plants. London: Academic Press.

Harvey, P. H. \& Pagel, M. 1991 The evolutionary method in comparative biology. Oxford University Press.

Harvey, P. H., Read, A. F. \& Nee, S. 1995 Why ecologists need to be phylogenetically challenged. J. Ecol. 83, 535-536.

Hutchings, M. J. \& de Kroon, H. 1994 Foraging in plants: the role of morphological plasticity in resource acquisition. Adv. ecol. Res. 25, 159-238.

Irmisch, T. 1850 Zur Morphologie der monokotylische Knollen- und Zwiebelgewächse. Berlin: G. Reimer Verlag. (In German.)

Jackson, J. B. C., Buss, L. W. \& Cook, R. E. 1985 Population biology and evolution in clonal organisms. New Haven: Yale University Press.

Kelly, C. K. 1994 On the economics of plant growth: stolon length and ramet initiation in the parasitic clonal plant Cuscuta europaea. Evol. Ecol. 8, 459-470.

Kelly, C. K. 1995 Thoughts on clonal integration: facing the evolutionary context. Evol. Ecol. 9, 575-585.

Klimeš, L., Klimešová, J., Hendriks, R. J. J. \& van Groenendael, J. M. 1997 Clonal plant forms: classification, distribution and phylogeny. In The ecology and evolution of clonal plants (ed. H. de Kroon \& J. M. van Groenendael). The Hague: SPB Academic Publishing. (In the press.)

Klimeš, L., Klimešová, J. \& Osbornová, J. 1993 Regeneration capacity and carbohydrate reserves in a clonal plant Rumex alpinus: effect of burial. Vegetatio 109, 153-160.

de Kroon, H. \& Schieving, F. 1990 Resource partitioning in relation to clonal growth strategy. In Clonal growth in plants: regulation and function (ed. J. M. van Groenendael \& H. de Kroon), pp. 113-130. The Hague: SPB Academic Publishing.

de Kroon, H., Fransen, B., van Rheenen, J. W. A., van Dijk, A. \& Kreulen, R. 1996 High levels of inter-ramet water translocation in two rhizomatous Carex species, as quantified by deuterium labelling. Oecologia 106, 73-84. 
de Kroon, H. \& van Groenendael, J.M. 1997 The ecology and evolution of clonal plants. The Hague: SPB Academic Publishing. (In the press.)

de Kroon, H. \& Hutchings, M. J. 1995 Morphological plasticity in clonal plants: the foraging concept reconsidered. J. Ecol. 83, 143-152.

Leakey, R. R. B. 1981 Adaptive biology of vegetatively regenerating weeds. Adv. Applied Biol. 6, 57-90.

Lovett Doust, L. 1981 Population dynamics and local specialization in a clonal perennial (Ranunculus repens) I. The dynamics of ramets in contrasting habitats. J. Ecol. 69, 743-755.

Marshall, C. 1990 Source-sink relations of interconnected ramets. In Clonal growth in plants: regulation and function (ed. J. M. van Groenendael \& H. de Kroon), pp. 23-41. The Hague: SPB Academic Publishing.

Mogie, M. \& Hutchings, M. J.(1990). Phylogeny, ontogeny and clonal growth in vascular plants. In Clonal growth in plants: regulation and function (ed. J. M. van Groenendael \& H. de Kroon), pp. 3-22. The Hague: SPB Academic Publishing.

Oborny, B. 1994 Growth rules in clonal plants and environmental predictability - a simulation study. J. Ecol. 82, 341-352.

Oborny, B \& Podani, J. 1996 The role of clonality in plant communities. Uppsala: Opulus Press. (In the press.)

Perttula, U. 1941 Studies on generative and vegetative reproduction of flowering plants from forest, meadow and rocky vegetation. Annales Botanicae Societatis ZoologiciBotanici Fennici Series A 58, 1-388. (In German.)

Pitelka, L. F. \& Ashmun, J. W. 1985 Physiology and integration of ramets in clonal plants. In Population boilogy and evolution in clonal organisms (ed. J. B. C. Jackson, L. W. Buss \& R. E. Cook), pp. 399-435. Newhaven: Yale University Press.

Purvis, A. \& Rambaut, A. 1995 Comparative analysis by independent contrasts (CAIG): an Apple Macintosh application for analysing comparative data. Computer Applications Biosci. 11, 247-251.

Rauh, W. 1937 Die Bildung von Hypocotyl und Wurzelsprossen und ihre Bedeutung fuer die Wuchsformen der Pflanzen. Nova Acta Leopoldina NF 4/24, 395-552. (In German.)

Salisbury, E. J. 1942 The reproductive capacity of plants. London: Bell.

SAS/STAT 1990 User's guide, 4th edn. Cary NG: SAS Institute.
Schmid, B. 1990 Some ecological and evolutionary consequences of modular organization and clonal growth in plants. Evolutionary trends in plants 4, 25-34

Shaver, G. R. \& Billings, W. D. 1976 Carbohydrate accumulation in tundra graminoid plants as a function of season and tissue age. Flora 165, 247-267.

Silander, J. A. 1985 Microevolution in clonal plants. In Population biology and evolution in clonal organisms (ed. J. B. G. Jackson, L. W. Buss \& R. E. Cook), pp. 107-152. New Haven: Yale University Press.

Slade, A. J. \& Hutchings, M. J. 1987 The effects of light intensity on foraging in the clonal herb Glechoma hederacea. J. Ecol. 75, 639-650.

Soukupová, L., Marshall, C., Hara, T. \& Herben, T. 1994 Plant clonality: biology and diversity. Uppsala: Opulus Press.

Stuefer, J. F., During, H. J. \& de Kroon, H. 1994 High benefits of clonal integration in two stoloniferous species, in response to heterogeneous light environments. J. Ecol. 82, $511-518$.

Stuefer, J. F., de Kroon, H. \& During, H. J. 1996 Exploitation of environmental heterogeneity by spatial division of labour in a clonal plant. Funct. Ecol. 10. (In the press.)

Sutherland, W.J. \& Stillman, R. A. 1988 The foraging tactics of plants. Oikos 52, 239-244.

Tiffney, B. H. \& Niklas, K. J. 1985 Clonal growth in land plants: a paleobotanical perspective. In Population biology and evolution in clonal organisms (ed. J. B. C. Jackson, L. W. Buss \& R. E. Cook), pp. 35-66. New Haven: Yale University Press.

Troll, W. 1937-1942 Vergleichende Morphologie der höheren Pfanzen, Band I-IV. Berlin: Verlag Gebrüder Bornträger.

Tuomi, J. \& Vuorisola, T. 1989 Hierarchical selection in modular organisms. Trends Ecol. Evol. 4, 209-213.

Velenovský, J. 1907-1913 Vergleichende Morphologie der Pflanzen Teil I-IV. Prague: Fr. Řivnáč Verlag. (In German.)

Watson, M. A. \& Casper, B. B. 1984 Morphogenetic constraints on patterns of carbon distribution in plants. $A$. Rev. Ecol. Syst. 15, 233-258.

Westoby, M., Leishman, M. R. \& Lord, J. M. 1995 On misinterpreting the 'phylogenetic correction'. J. Ecol. 83, 531-534.

Widén, B., Cronberg, N. \& Widén, M. 1994 Genotypic diversity, molecular markers and spatial distribution of genets in clonal plants, a literature survey. In Plant clonality: biology and diversity (ed. L. Soukupová, G. Marshall, T. Hara \& T. Herben), pp. 139-157. Uppsala: Opulus Press. 